\title{
The predictable evolution of letter shapes: An emergent script of West Africa recapitulates historical change in writing systems
}

\author{
Piers Kelly \\ James Winters \\ Helena Miton \\ Olivier Morin
}

\begin{abstract}
A familiar story about the evolution of alphabets is that individual letters originated in iconic representations of real things. Over time, these naturalistic pictures became simplified into abstract forms. Thus the iconic ox's head of Egyptian hieroglyphics transformed into the Phoenician $\mathcal{\forall}$ and eventually the Roman letter A. In this vein, attempts to theorize the evolution of writing have tended to propose variations on a model of unilinear and unidirectional progression. According to this progressivist formula, pictorial scripts will tend to become more schematic while their systems will target smaller linguistic units. Objections to this theory point to absent, fragmentary or contrary paleographic evidence, especially for predicted transitions in the underlying grammatical systems of writing. However, the forms of individual signs, such as the letter A, are nonetheless observed to change incrementally over time. We claim that such changes are predictable and that scripts will, in fact, become visually simpler in the course of their use, a hypothesis regularly confirmed in transmission chain experiments that use graphic stimuli. To test the wider validity of this finding we turn to the Vai script of Liberia, a syllabic writing system invented in relative isolation by non-literates in ca. 1833. Unlike the earliest systems of the ancient world, Vai has the advantage of having been systematically documented from its earliest beginnings until the present day. Using established methods for quantifying visual complexity we find that the Vai script has become increasingly compressed over the first 171 years of its history, complementing earlier claims and partial evidence that similar processes were at work in early writing systems. As predicted, letters simplified to a greater extent when their initial complexity was higher.
\end{abstract}

Keywords: evolution of writing, cultural evolution, Vai, paleography

Note: This is a preprint, accepted for publication by Current Anthropology on February 112020 , and scheduled for release in 2021. It is posted here in full compliance with CA guidelines under a CC BY-NC license. Cite as: Kelly, Piers, James Winters, Helena Miton, and Olivier Morin. forthcoming. "The predictable evolution of letter shapes: An emergent script of West Africa recapitulates historical change in writing systems" Current Anthropology. 1-38. 


\section{Introduction}

3 If all writing systems undergo observable historical change, is it possible to identify

4 the underlying evolutionary processes and predict their trajectories? A long-discussed hypothesis holds that new scripts become visually simpler and more systematic as they are transmitted from generation to generation over historical time (Trigger 2003, 600-602, Changizi and Shimojo 2005, Dehaene 2009). One of the greatest challenges in testing this claim is the fact that we do not have a complete record of the first writing systems, especially in the earliest years of their development. We address this problem by drawing on data from the Vai script of Liberia, a syllabary developed in isolation by non-literates in ca. 1833 and still in use today. We find that Vai letters have become more compressed over the first 171 years of their history, and suggest that this finding has broad applicability to the evolution of early writing systems.

One of the earliest to articulate a theory of the evolution of writing was Rousseau who proposed that writing passed through three stages, from pictures, to whole words, and finally alphabets. "The depicting of objects is appropriate to a savage people;" he wrote in his Essai sur l'origine des langues, "signs of words and of propositions, to a barbaric people, and the alphabet to civilized peoples [peuples policés]." (Rousseau [1781] 1966, 17). This basic proposition was to remain largely unchallenged for nearly two centuries, but the sensational decipherment of Egyptian hieroglyphics on the part of Champollion (1824) generated a new wave of interest in the evolution of writing. Contrary to Champollion's expectations, the Egyptian hieratic script was apparently far cruder in its form than the monumental hieroglyphic script that had preceded it, which lent the impression that it was regressing to a more 'primitive state' (Champollion 1836). In response, the sinologist Pauthier addressed the apparent contradiction of style and chronology in Egyptian scripts, maintaining that progressive schematisation was a defining process in the evolution of writing. In an upgrade to Rousseau's tripartite model, Pauthier postulated a so-called figurative age of writing that was characterised by pictorial representations of objects, while in a subsequent transitory age these iconic images become more conventional and abstract. In a final pure alphabetic age only the simplest phonological elements were represented in graphic form. Alphabets were thus doubly compressed. Not only were they simpler in the outward shape of their scripts, but their underlying orthographic 
1 systems were reduced to the bare phonemic essentials. Illustrating this progression,

2 Pauthier referred to documented changes in both Egyptian and Chinese writing

3 systems toward greater abstraction and simplicity. In his estimation, the process could

4 even be invoked as a method for dating paleographic inscriptions since it was a law

5 that "suffered no exception" (Pauthier 1838, 567). Later, the classicist Ritschl would

6 seek to formalise a new "scientific paleography" that recognised that historical script

7 change was not arbitrary but a matter of "internal development" governed by "certain

8 laws and guiding impulses" (Ritschl 1869)'.

9 Independently of the French and German tradition, Morgan and Tylor were to reinvent Rousseau's evolutionary stages of writing in the context of their more

11 ambitious teleological model of human progress. For Morgan, a society's use of 12 alphabetic writing, as opposed to other systems, was diagnostic of its ascension to the 13 highest status of civilisation. Tylor was even more explicit in linking technological 14 changes, such as a shift from stonework to metalwork, with transitions from 'picturewriting' to the alphabet (Tylor [1865] 1878, 374). For the progressivists, therefore, there was an implied inverse relationship between the (perceived) complexity of a society's material culture and the outward simplicity of its writing system.

Although progressivism was to be roundly rejected from within anthropology it found fertile ground in the field of grammatology. Taylor (1883a, b), Clodd (1900), 20 Ege (1921), Mason (1928), Gelb ([1952] 1963) and Cohen (1958) gave the social evolutionist framework a renewed impetus in their stadial formulas for the evolution of writing. Their chief theoretical differences lay only in the number of discrete stages that writing was supposed to pass through on the road to alphabetic abstraction.

\section{Schematization as a general law}

Nineteenth-century European scholars often wondered whether the proposed principle of progressive schematisation might be applicable to symbolic behaviour more generally. Pitt-Rivers and Balfour assessed graphic artefacts collected in colonial settings-including New Ireland paddles, Peruvian pottery and decorated spear shafts from the Solomon Islands - and attempted to arrange them in sequences

30 from the most representational to the most schematic. This exercise was intended to 31 illustrate how figurative forms become conventionalised through constant 32 reproduction, with their superfluous features falling away in the process: 
[...] thus the drawing of a stag would be made to convey information to people at a distance that there was a herd of deer in the neighbourhood to be hunted; and as the object of the drawing was no longer to depict truthfully the peculiarities of the beast, but merely to convey information, the amount of labour expended upon it would be the least that could be employed for the required purpose. All written characters have originated in this way; and no one now requires to be told how pictographic representations developed into hieroglyphic and subsequently into phonetic characters. (Pitt-Rivers [1875] 1906, 40)

Graphic communication systems, be they cave paintings or writing systems, were therefore seen to follow a principle of least effort. One of the presumed mechanisms for schematisation was to be found in the imperfect reproduction of a graphic figure over successive iterations. Accordingly, Balfour emphasised the role of "unconscious variation" whereby "the changes are not intentional, but are due to want of skill or careless copying, difficulty of material, or reproducing from memory" (Balfour 1893, 77). Reprising Pitt-Rivers, he maintained that figurative art must surely have been ancestral to modern alphabetic writing (Balfour 1893, 98).²

Balfour was also the first to develop experiments for testing the effects of cultural transmission on items of symbolic culture. In Balfour's tasks an experimental participant was asked to create a sketched reproduction of a picture, and this sketch was then copied by a second participant, and so on. According to his contemporary, the French philosopher Philippe, these kinds of experiments revealed a "law of economy", by which "unnecessary details fall and disappear to make room for what is necessary for the whole", adding that such transformations must scale up to broader cultural changes at the population level (Philippe 1897, 493).

Bartlett would later design similar pencil-and-paper tasks with the aim of testing the dynamics of human memory. Noticing that figurative images tended to become simpler and more conventionalised over successive "generations", he perceived a real-world parallel in the historical evolution of writing systems whereby "realistic pictures" eventually became "non-representational conventional signs" (Bartlett [1932] 1995, 95). So taken was he by this observed correspondence that he was inspired to use Native American pictograms and Egyptian hieroglyphics as the primary input for a number of his experimental tasks $(97,180) .{ }^{3}$ In a more recent example, Simon Garrod et al. (2007) developed Pictionary-style graphic tasks that detected a transition towards non-iconic simplicity leading them to speculate that similar processes must have underpinned the loss of iconicity in the cuneiform and 
1 Chinese writing systems over deep time-scales. One preliminary attempt to compare complexity rates in natural writing systems was made by Hegenbarth-Reichardt and Altmann (2008) who applied a hand-coded method to show that a specific historical instantiation of the hieratic script was quantifiably simpler than the hieroglyphic script used in the same period.

\section{A revised hypothesis on the evolution of letter forms}

7 A unifying argument across these disparate fields, from nineteenth century paleoanthropology to contemporary transmission-chain experiments, is that graphic forms proceed through a process of simplification that transpires in the course of their recollection and reproduction by individual writers, and their transmission from one individual to another. However, the term compression is a more accurate descriptor than simplification for this process. In other words, through repeated interactions, a system of signs will become compressed so that the same amount of information is expressed with less descriptive effort. Although this proposition is well confirmed under controlled experimental conditions (Tamariz 2017), it not always clear how it might apply to the dynamics of real-world historical change in writing systems.

It is remarkable, after all, that the world's earliest independent writing systems have all exhibited extensive iconicity, and that in many instances this iconicity diminished in later forms or derivatives of the script. As a counter-observation one could point out that simple and non-figurative symbols were already in wide use at the dawn of writing in Mesopotamia, or that iconicity in Egyptian hieroglyphics was retained over the entire history or the script. Meanwhile, the Olmecoid scripts of Mesoamerica are apparently less figurative than the Maya script that post-dates them archeologically (Mignolo 1989, Downey 2014), while the Maya script itself retained its complexity and iconicity. These, however, are not falsifying examples. We do not yet know whether the pre-Maya scripts of Mesoamerica were glottic writing (representing language) nor if they have a direct historical relationship to the better attested Maya script; just as the abstract markings on neolithic Chinese pottery cannot be proven to be ancestral to early Chinese writing. As for Egyptian writing, there is no doubt that the more schematic hieratic script was derived from Egyptian hieroglyphics and not the other way around (Altenmüller 2005, but see Goedicke 1988, vii-viii).

32 Moreover, hieroglyphics existed in a rich graphic context that included not just 
1 hieratic and demotic scripts, but an artistic tradition with a well-defined repertoire of 2 figurative forms (Baines 2007).

In short, a minimal hypothesis that early scripts evolve in the direction of visual simplicity is not, on the face of it, controversial. What could cause this bias is not quite as evident. We propose that it is driven by a least effort principle (inspired by Zipf 1949). This phrase is usually linked to the fact that spoken languages tend to minimize the total amount of effort that speakers invest in producing words, by shortening frequently pronounced words, which are also the least informative (Zipf 1949; Piantadosi, Tily, and Gibson 2011). We endorse the general notion that symbols their information content. This principle is in line with the broader view that communicative signals face a trade-off between simplicity and informativeness. Applied to lexicons, the principle successfully predicts that fine-grained categorisations apply to the more salient, relevant, or frequently communicated elements, while coarse-grained categorisations are reserved for less important traits, in both natural languages and in artificial codes evolved in the lab (Regier, Kemp, and Kay 2014, Carr et al. 2017).

We apply this principle to writing (departing from Zipf in doing so). Our version of the least effort principle states that writers are motivated to reduce their cognitive and motor exertion when tracing a letter, up to the point where further simplification would make the letter undistinguishable from other letters. This principle does not predict a continuous progress of increasing simplification, nor does it assume that all scripts should reach the same level of complexity over time. Quite the contrary. Simplification should stop around the point where it imperils legibility, making letters too difficult to distinguish from one another, and it predicts this because a decrease in legibility entails a potential increase in future effort. Where this point lies is likely to differ from script to script: letters are distinctive for various reasons in various scripts. The very pressure to stand out as a distinctive letter would be less intense in a small alphabet, compared to a 200-letter syllabary. Our hypothesis, thus, is quite compatible with the fact that the scripts used by the world's writing systems vary considerably in complexity. It can also accommodate the possibility that most scripts are not currently becoming simpler. 
1 Character complexity is not solely driven by the cognitive and motor factors listed above, but also by variable technological factors (e.g. means of letter inscription, etc.) or historical contingencies (weight of precedent; contact with other writing systems). We make no specific predictions about these culturally and historically contingent factors, except to stress that they may complicate the account given here in unpredictable ways, making the data noisier, so to speak. For this reason, our theoretical framework does not predict that two culturally distinct writing systems should necessarily evolve to reach the exact same degree of letter complexity over time (even assuming both systems encode the exact same language in the exact same way). In particular, we cannot rule out the possibility that a script's initial complexity could cast a long shadow over its subsequent evolution, making it likely that initially complex scripts stabilise at a higher level of complexity than ones that were initially less complex.

This still does not tell us why letter shapes should be overly complex from the outset. In theory, the mechanism just described could result in a process of complexification, where overly simple letters get enriched until they become sufficiently distinctive. We do think that in theory, such a process should happen, and that some actual examples may be found. Scholars have pointed to potential complexification processes at work in the Aztec and Mixtec scripts (Boone 1994, Downey 2014), certain Linear A inscriptions (Steele 2017, 165), and later forms of Ogham (McManus 1996). Complexification, or inertia, may set in when writing systems are employed primarily for symbolic, aesthetic or religious purposes; or when the inscriptions are intended to be displayed for long periods of time.

Yet, we also concur with the literature just reviewed: the trend usually goes from complex to simple. Why would this be? Here is one possible answer. The need for letters to be distinctive is immediately apparent to the eye of a script inventor. To estimate, and then to reduce, the precise amount of effort that goes into tracing a letter, would presumably take longer. The differentials are minute, becoming significant only when a letter is repeatedly traced millions of time. It would thus make sense for script inventors to overlook the discrete costs of letter production, and favor distinctiveness over simplicity. A related pressure leading to initial complexity is the fact that, from an inventor's point of view, ease of imagination and recall (pushing for distinctiveness) may matter more than ease of production. 
In some ways, the process we are positing resembles cursivization, another wellknown evolutionary trend that affects writing systems, the Egyptian and Latin scripts being the clearest examples (Coulmas 2003; Parkes 2008). Cursivization occurs when a script starts being written much more frequently and rapidly than it used to be-by copyist monks in the Latin case-linking letters together, producing rounded shapes and ligatures. Cursivization may or may not produce simplified shapes (it did in the case of Egyptian hieratic; Hegenbarth-Reichardt and Altmann 2008). In any case, it has much in common with simplification. It is a gradual process driven by a principle of least motor effort that may come into conflict with letter distinctiveness; in the Latin case, cursivization produced such ambiguous pairs as $\mathrm{p}$ and $\mathrm{q}$ or $\mathrm{n}$ and $\mathrm{m}$. Cursivization is common and its effects are recognizable in various unrelated scripts, but is neither a universal process, nor one that fashions every script into the same identical shapes.

The view that cultural change is somehow geared toward particular states has recently been defended by "cultural attraction theory" (Sperber 1996; Morin 2015; Scott-Phillips, Blancke, and Heintz 2018), a school of thought working within the broader framework of cultural evolution (Cavalli-Sforza and Feldman 1981; Boyd and Richerson 1985). Its goal is to identify "attractors", i.e., states that cultural dynamics tend to evolve toward unless they are in that state already. Attraction dynamics are well explored experimentally (Kalish, Griffiths, and Lewandowsky 2007, Fehér et al. 2009, Miton, Claidière, and Mercier 2015). We contend that letter shapes satisfying a principle of least effort are such an attractor: scripts should evolve toward that state unless they are already there.

\section{Iconicity versus visual complexity}

If, therefore, the material shape of writing is subject to processes of schematisation, from iconic to abstract, how is such change to be measured or predicted? The problem faces a number of immediate challenges. Firstly, the property of iconicity is hard to capture and measure objectively given the cross-cultural diversity of figurative traditions and their context-specific perceptions of verisimilitude. This inherent subjectivity of iconicity judgements is succinctly expressed by Morphy, a visual anthropologist who has defined figurative representations as those that are "intended to 'look like' the object represented and to be interpreted as such by those familiar 
$1 \quad$ with the iconographic code." (Morphy 1991, 152, emphasis added). Added to this is 2 the problem that even within a single visual tradition there is no robust way of determining whether a given sign is more or less iconic than another (but see McDougall, Curry, and de Bruijn 1999). We, however, argue that the tendency for graphic images in transmission experiments to lose iconicity over multiple generations is subordinate to a more fundamental transition from less compressible to more compressible. That is to say, the images (iconic or otherwise) become graphically optimised in terms of information storage, retrieval and reproduction by human agents. We do not claim that graphic iconicity itself is an encumbrance with no role or affordance (see for example Turoman and Styles 2017), but rather that the diachronic measurement of iconicity is neither feasible nor desirable, let alone the measurement of its presumed effects. In other words, whether or not an insider observer perceives a loss or maintenance of iconicity across the full history of a writing system is of far less relevance to whether the writing system, both the individual items and the set of items, is becoming more or less compressed over time, or remaining stable.

\section{Emergent writing systems and what they might tell us}

Probing for compression effects in ancient primary inventions of writing is difficult since there is no way of reconstructing the very early phases of the development of writing as it unfolded year by year from individual to individual. ${ }^{4}$ In short, the surviving archeological record does not permit us to observe how incremental processes of change and variation, witnessed over very short time-spans, might scale up to larger patterns over generations, centuries and millennia. And if we turn instead to later and better-documented periods in the history of writing it becomes hard, if not impossible, to disentangle the effects of inheritance from other processes.5

One proposal, by no means original, is to turn instead to secondary inventions of writing generated via stimulus diffusion. These are systems created in near isolation by non-literate inventors who borrowed the idea of writing but did not directly acquire its principles directly from literate teachers. Terminology for this special class of secondary scripts varies, however we prefer 'emergent scripts' (by analogy with

31 'emergent languages') and define them as functional writing systems developed by non-literates from minimal stimulus. ${ }^{6}$ 
Both Tylor ([1865] 1878) and Kroeber (1940) recognised the potential of emergent systems to illustrate general processes of cultural borrowing, diffusion and change.

Other scholars, meanwhile, argued that they might also serve as heuristics for probing the origin and evolution of writing itself across deep time-scales (Diringer [1948] 1968, Gelb [1952] 1963, Dalby 1967, Kotei 1972, Ferguson 1995). Isolated reinventions of writing serve as naturalistic transmission experiments in script change since the non-literate inventors taught their systems to new generations of nonliterates who have in turn passed their knowledge to subsequent generations. Writing has been reinvented under these conditions at least seven times in recent history. The best known example is that of the Cherokee script developed by Sequoyah in 1821. This was followed soon after by the Vai script (Liberia, ca. 1833), the Bamum script (Cameroon, ca. 1896), the Alaska script (1901-1905), the Caroline Islands script (1905-1909), the Masaba script (Mali, 1930), and Pahawh Hmong (Vietnam, 19551971).

Of these scripts we contend that the Vai script of Liberia (Fig. 1) is the best candidate for historical analysis. The script was created by at least eight men (Forbes 1851) who had probably been exposed to the Arabic and Roman scripts but were not literate in either of them and certainly did not apply them as models, unlike the Cherokee syllabary that took direct inspiration from the Roman alphabet.? While Roman and Arabic scripts were certainly used in West Africa by a literate minority in the early 19th century, no influence is discernible in early or later forms of the Vai letters. Indeed, a powerful indication that the inventors of Vai were not literate in the segmental Roman and Arabic scripts is the fact that the Vai writing system is a syllabary (Daniels 1992, 88). Although the Vai script was sporadically taught in local schools, its transmission has remained largely informal and non-institutionalised for most of its history. Until recently, those who wished to learn the language had to seek out a literate individual to teach them on a voluntary basis (Scribner and Cole 1981; Bai Leesor Sherman, pers. comm.). The teaching itself follows no prescribed method: there is no recitation order nor any common reference syllabary meaning that apprentices learn-by-doing (Konrad Tuchscherer, pers. comm.). Thus, if certain characters are not needed in a communication, there may never be occasion to learn them at all. ${ }^{.}$The fact that the number of graphemes in the system did not substantially expand or contract from its inception up until the present day means that the pressure 
1 for distinguishability of letters has not appreciably changed over its history. Vai is 2 also a wholly secular writing system that has always been used for ordinary 3 communicative purposes such as letter writing and household administration as 4 opposed to display or ritual. For all these reasons we might expect that Vai writers 5 have used their scripts under conditions of relative freedom giving variation and 6 change the best chance to emerge. Finally, the script has been independently 7 documented on at least sixteen separate occasions between 1834 and 2005 meaning 8 that almost all of its history is recorded and does not require any interpretive 9 reconstruction.

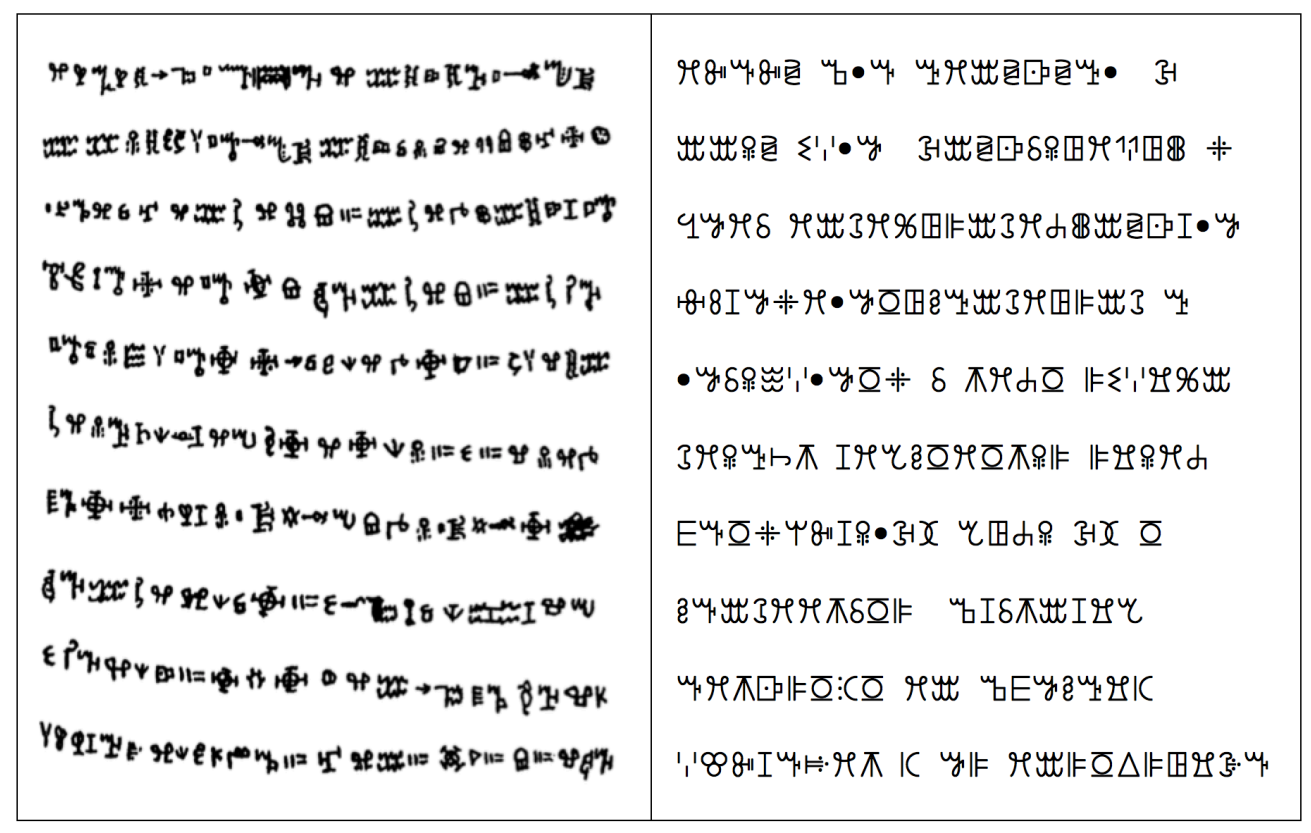

Figure 1. Left: The earliest surviving record of the Vai script, dated 1834. Right: The same text written in the modern (2005) version of the script.'

The Vai script remains in active use today among Vai speakers, however the devastations of the Liberian Civil Wars (1989-1997, 1999-2003) and the West African Ebola Crisis (2013-2016) have had some impact on its domains of use and the distribution of its users. Prior to these events, the script had a more prominent role in formal communications between Vai chiefdoms, especially in the coordination of elections for the Traditional Council of Chiefs. During the Ebola Crisis, meanwhile, the Vai script was mobilized within Cape Mount as a medium for promoting health and quarantine regulations. Vai program officers used the script to display warnings 
1 and directives on public placards and to distribute messages among Vai communities.

2 Another significant change in recent years is that fact that the script is now being

3 taken up by learners who are not ethnically Vai. This has been noticed among

4 students at the University of Liberia campus in Sinje, Grand Cape Mount County.

5 An analysis of compression in the Vai script

6 Drawing on manuscript sources we proposed to measure compression in the Vai

7 script as it has evolved between 1834 until 2005. The Vai script has roughly 200

8 graphemes (inventory sizes vary slightly depending on the source and historical time

9 period) representing CV syllables of the Vai language, and some logograms.

10 The Vai script has previously been treated as a case study for exploring synchronic 11 distributions of complexity in writing systems (Rovenchak, Mačutek, and Riley 2009, 12 Rovenchak, Riley, and Sherman 2011). These studies attempted to find correlations 13 between the frequency of given graphemes and their complexity, with inconclusive 14 results. They relied on manual coding of overt features within individual graphemes, 15 as developed by Altmann (2004) and Peust (2006). A single point, for example, is 16 assigned a value of one, a straight line a value of two an intersecting line a value of 17 three, etc. Our study, however, analyses the graphemes in terms of their descriptive 18 and perimetric complexity by means of semi-automated computational processes. 19 Descriptive complexity refers to how simply an image can be described in 20 mathematical terms, while perimetric complexity captures the size of an image's 21 perimeter independent of its scale. These methods have the advantage of 22 circumventing the potential subjectivity of hand-coding and have precedents in other 23 studies (for example, Pelli et al. 2006, Caldwell and Smith 2012, Tamariz and Kirby 24 2015, Miton and Morin 2019).

25 Our measure of perimetric complexity is taken from Watson (2012) since this 26 procedure has proven effective at measuring relatively simple images, including the 27 graphemes of writing systems. Descriptive complexity, meanwhile, is measured by 28 recording the file size of images that are compressed to a zip format (following 29 Tamariz and Kirby 2015). 


\section{Analysis of historical dataset}

2 Our dataset consists of individual Vai graphemes from 16 sources dated between 1834 and 2005, as tabulated by Tykhostup and Kelly (2018). Each source is constructed so that the set of graphemes is associated with a date (e.g., 1909) and an author (e.g., Migeod). Tykhostup \& Kelly's aim was to provide a meaningful comparative data set for the history of the Vai script such that any transformations of individual graphemes might be tracked over 171 years. All available archival sources where consulted in order to assemble the dataset presented in that paper, however, texts that were either undated or too short were necessarily excluded. It should also be noted that the final source is a Vai unicode proposal (Everson, Riley, and Rivera 2005). Though modelled to some extent from earlier materials (especially Kandakai et al. 1962) we regard this latest instantiation of the script as a dateable 'source' that is no less historically significant for being a digital document. Tykhostup \& Kelly did not have access to dated manuscripts after 2005, which is why more recent sources are not included.

The data, while extensive in comparison to other emergent scripts, is not exhaustive and is limited to what has survived in the documentary record. Notable gaps include the period of the two world wars, and the Liberian civil wars (19892003). It is plausible for example, that variant graphemes branched off to create new lineages that became extinct and were thus not represented in surviving archives. We cannot know the degree of compression in these hypothetical lost lineages. For the purposes of analysis our dataset is further limited to the life histories of only the bestattested Vai graphemes. Thus, a Vai grapheme is included in the dataset if a) it is attested in at least 90 percent of the historical sources, and b) there are surviving examples in both the earliest source (1934-ca. 1845) and the most recent source (2005). This reduces our analysis to 61 graphemes (although not all 61 are attested in each source). Such a constraint weights the sample in favour of more frequent syllables in the Vai language since these are more likely to turn up in documentary sources.

To ensure consistency and accuracy each grapheme was extracted from a digital image of the original manuscript source, opened in Adobe Illustrator and then virtually traced as a vector over the exact contours of the original image, a method widely used by epigraphers to ensure the accurate comparative analysis of inscriptions 
1 (Parker and Rollston 2016). Further we applied a consistent stroke width and placed 2 each letter within a bounded area of $1121 \times 776$ pixels. Next, each grapheme was exported in both .png and .svg formats. For all images, the foreground colour of the grapheme is white, and the background colour is black. All 2128 processed images, including the originals, are permanently archived in an open-access, open-data Figshare repository. ${ }^{10}$ As .svg images are vector-based, the graphemes are represented by $2 \mathrm{D}$ points that are connected via lines and curves to form shapes. We then apply two measures of visual complexity for each instantiation of the 61 graphemes across 16 time periods.

Perimetric complexity (henceforth, PC) measures the complexity of binary pictures by taking the squared length of the inside and outside perimeters of a grapheme $P$, divided by the foreground area $A$ and by $4 \pi$ (Pelli et al. 2006; Watson 2012)":

$$
C=\frac{P^{2}}{4 \pi A}
$$

13 Our second measure takes the vector representation of drawing (.svg file) and then applies the DEFLATE compression algorithm to remove any redundancies (following Tamariz and Kirby 2015). This method approximates the descriptive complexity (henceforth, DC) of each grapheme: the amount of information required to losslessly describe a grapheme in terms of vector paths and anchor points.

Preregistered predictions

Our general hypothesis is that repeated episodes of transmission amplify a bias for simplicity and this impacts the visual complexity of Vai graphemes. It is important to note that our hypothesis is principally concerned with the evolution of each individual character as opposed to the set of characters (Claidière et al. 2018). As such, we ignore factors such as an increased similarity between characters within a set, and instead focus on whether or not a particular grapheme becomes more or less visually complex. In particular, we test three predictions:

Prediction 1: Visual complexity will decrease over successive generations.

28 Prediction 2: The complexity of graphemes with higher visual complexity will decrease more than those with initially lower scores. 
1 Prediction 3: Variance in complexity among characters should decrease with 2 successive versions of the script.

3 These three predictions were preregistered on the Open Science Framework on 4 September 9, 2017. Our predictions were meant to apply to two distinct studies: the 5 present study, based on historical data, and a transmission chain experiment. The 6 results of the transmission chain experiment will be published separately. This paper 7 also reports on follow-up analyses that were not preregistered but were suggested by

8 reviewers.

\section{Does visual complexity decrease over successive generations?}

10 To test our first prediction, we constructed two distinct analyses for the dependent 11 variables of PC and DC. Both analyses are performed using a mixed effect model (Bates et al. 2014) with individual characters being considered as the basic unit of analysis, nested inside the year of the script. For instance, the character $\mathbb{T}<\mathrm{ga}>$ as

14 instantiated in the 1868 version of the script counts as a single datapoint. Year is used 15 as the sole predictor in our model ${ }^{12}$. This allowed us to test whether changes in our 16 dependent variables are predicted by the progression of time. We expected a negative 17 effect for both analyses (i.e., both PC and DC decrease over time). Lastly, it is likely the case that individual characters will follow different trajectories through time; to control for this variation we specified character as a random intercept (i.e., different versions of the character within a year are free to vary on the intercept) and included a

21 random slope for year (which accounts for the fact that characters can vary year-on22 year in terms of complexity).

\begin{tabular}{|c|c|c|c|}
\hline & AIC & BIC & $\operatorname{Pr}(>$ Chisq $)$ \\
\hline Null Model & 5596.4 & 5621.2 & \\
\hline \multirow[t]{3}{*}{ Year } & 5574.5 & 5604.3 & $1.013 \mathrm{e}-06^{\star \star \star}$ \\
\hline & & & $(\star \star \star \star)<0.001$ \\
\hline & AIC & BIC & $\operatorname{Pr}(>$ Chisq $)$ \\
\hline Null Model & 9808.9 & 9833.7 & \\
\hline \multirow[t]{2}{*}{ Year } & 9800.7 & 9830.5 & $0.00138^{\star \star}$ \\
\hline & & & 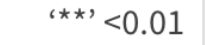 \\
\hline
\end{tabular}

${ }^{1}$ The preregistered document can be consulted at https://osf.io/8gw5a/. 
Table 1. Model comparisons for PC (top) and DC (bottom) using AIC and BIC. A

null model, e.g., PC $1+(1+$ Year | Character $)$, was compared to a model where Year was entered as a predictor, e.g, PC $\sim$ Year $+(1+$ Year | Character $)$.

Figs. 2 and 3 show the respective averages for PC and DC. In both cases, we observe a general trend towards a decrease in visual complexity, which is confirmed by the model results for both PC (Intercept: $\beta=16.128$, Year: $\beta=-0.019$ ) and DC (Intercept: $\beta=517.196$, Year: $\beta=-0.100$ ). The negative coefficients in these models are significant when compared to Null models (i.e., without Year as a predictor $)^{13}$. The significant effect of Year tells us that this negative trend is robust, even when accounting for individual variation in changes to character complexity over time. To illustrate, if one character happens to increase in complexity over time, then the model controls for this fact in determining the overall effect of year. Conversely, the model also accounts for any steep decreases in complexity for individual characters, which means our results are not simply an artefact of a single character disproportionately influencing the average trend.

\section{Do graphemes with higher visual complexity decrease more than graphemes with initially lower complexity?}

Simplifying effects are predicted to be dependent on the initial complexity of the grapheme. Specifically, our claim is that graphemes with initially high visual complexity are more likely to decrease than graphemes that start out with low complexity. The rationale being that low complexity graphemes are already extremely optimized and unlikely to deviate much in terms of complexity, as observed in transmission chain studies, where compressed items stabilize at a certain point of optimization (Tamariz and Kirby 2015, 182). Conversely, graphemes with initially high complexity are not optimized for simplicity, and are thus predicted to decrease over time (assuming a directional effect for simplicity). To test this prediction, two ordinal ranks were constructed for both PC and DC based on their respective scores for 1834. This provides us with a baseline for the initial grapheme complexity. The ranks go from 0 (lowest score) to 37 (highest score) for PC and 0 (lowest score) to 31 (highest score) for $\mathrm{DC}^{14}$. Ordinal measures were used for both Year and Rank to 
1 mitigate differences in scale causing convergence errors. As with the first prediction,

2 we conducted separate mixed effect regression analyses for PC and DC, but have now

3 added Rank as an interacting predictor with Year.

\begin{tabular}{|c|c|c|c|}
\hline & AIC & BIC & $\operatorname{Pr}(>$ Chisq $)$ \\
\hline Year-Only & 6383.7 & 6410.9 & \\
\hline Year * Complexity Rank & 6361.2 & 6397.5 & $\begin{array}{l}1.817 \mathrm{e}-06^{\star * \star} \\
\text { (***) }\end{array}$ \\
\hline & AIC & BIC & $\operatorname{Pr}(>$ Chisq $)$ \\
\hline Year-Only & 3551.8 & 3579.0 & \\
\hline Year * Complexity Rank & 3524.3 & 3560.6 & $\begin{aligned} & 1.445 \mathrm{e}-07^{\star \star \star} \\
&\left.{ }^{\star \star \star \star \star}\right)<0.001\end{aligned}$ \\
\hline
\end{tabular}

Table 2. Model comparisons for DC (top) and PC (bottom) using AIC and BIC. Each comparison involved a model with Year specified as the only predictor (Year-Only), e.g., PC Year + (1+Year | Character $)$, and Year interacting with the initial complexity rank, e.g., PC Year * Complexity Rank + (1+Year | Character $)$.

It seems that adding initial grapheme complexity (Complexity Rank) as an interacting predictor does improve the model fit for both PC and DC when compared to a model with only Year as a predictor. Furthermore, the interaction between year and initial grapheme complexity for PC (Intercept: $\beta=9.95$, Year*Complexity Rank: $\beta=-0.01$ ) and DC (Intercept: $\beta=450.91$, Year*Complexity Rank: $\beta=-0.20$ ) indicates that later years and higher initial grapheme complexity correspond to decreases in PC and DC (Figs. 4 and 5). This supports our general hypothesis that differences in visual complexity are important in determining the change in complexity over time: graphemes with initially higher complexity are likely to follow a steeper decrease over time than graphemes with initially lower complexity.

Does variance in complexity among graphemes decrease with successive versions of the script?

24 To test for a decrease in variance in complexity with successive versions of the script, 25 we used a Levene's test for homogeneity of variance (1) on all samples from 1834 to 2005, and (2) between the first (1834) and the last (2005) available datasets. On all 
1 samples, the Levene's test indicated unequal variances for both descriptive ( $F(14$, $21048)=1.83, p<.05)$ and $\mathrm{PC}(F(14,1048)=2.21, p<.01)$. In testing for a decrease in 3 variance between our first and last available datasets, we observed that variance was 4 higher in 1834 than in 2005 for both DC and PC (Figs. 4 and 5). This decrease is 5 significant for descriptive complexity $(\mathrm{F}(1,97)=4.09, \mathrm{p}<.05)$ but not for perimetric 6 complexity $(\mathrm{F}(1,97)=2.66, \mathrm{p}=.11)$, as shown in Table 3 .

7

\begin{tabular}{|l|l|l|}
\hline & 1834 & 2005 \\
\hline Descriptive complexity & $\begin{array}{l}3994.98 \\
{[2174.54,5815.42]}\end{array}$ & $\begin{array}{l}1089.64 \\
{[699.73,1479.56]}\end{array}$ \\
\hline Perimetric complexity & 24.57 & 10.83 \\
& {$[13.38,35.77]$} & {$[6.95,14.70]$} \\
\hline
\end{tabular}

8 Table 3. Variance in descriptive and perimetric complexity, in 1834 and 2005. The 9 values between brackets indicate bootstrapped $95 \%$ CIs. 


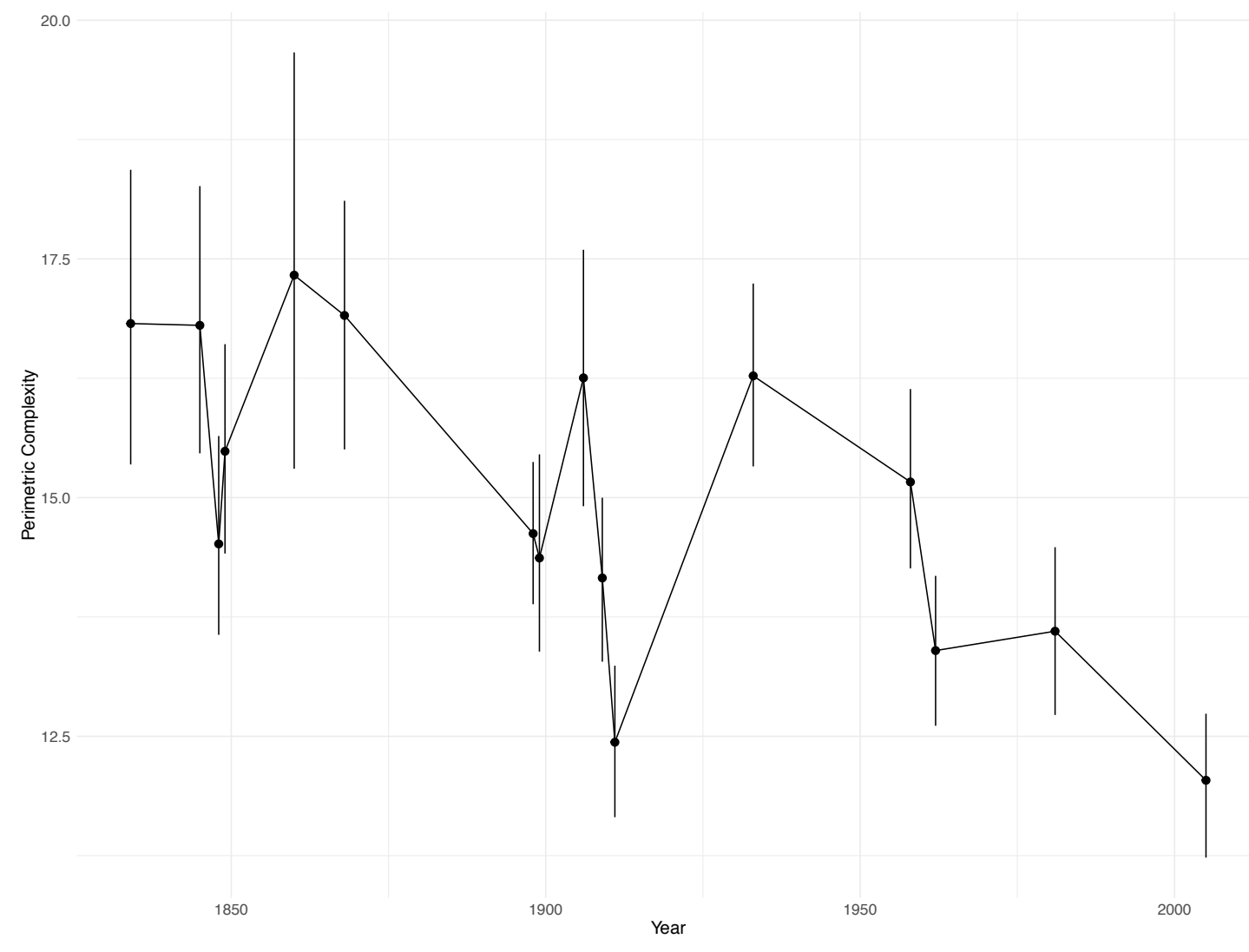

2 Figure 2. Mean perimetric complexity from 1834 to 2005. Error bars correspond to $395 \%$ CIs (bootstrapped). 


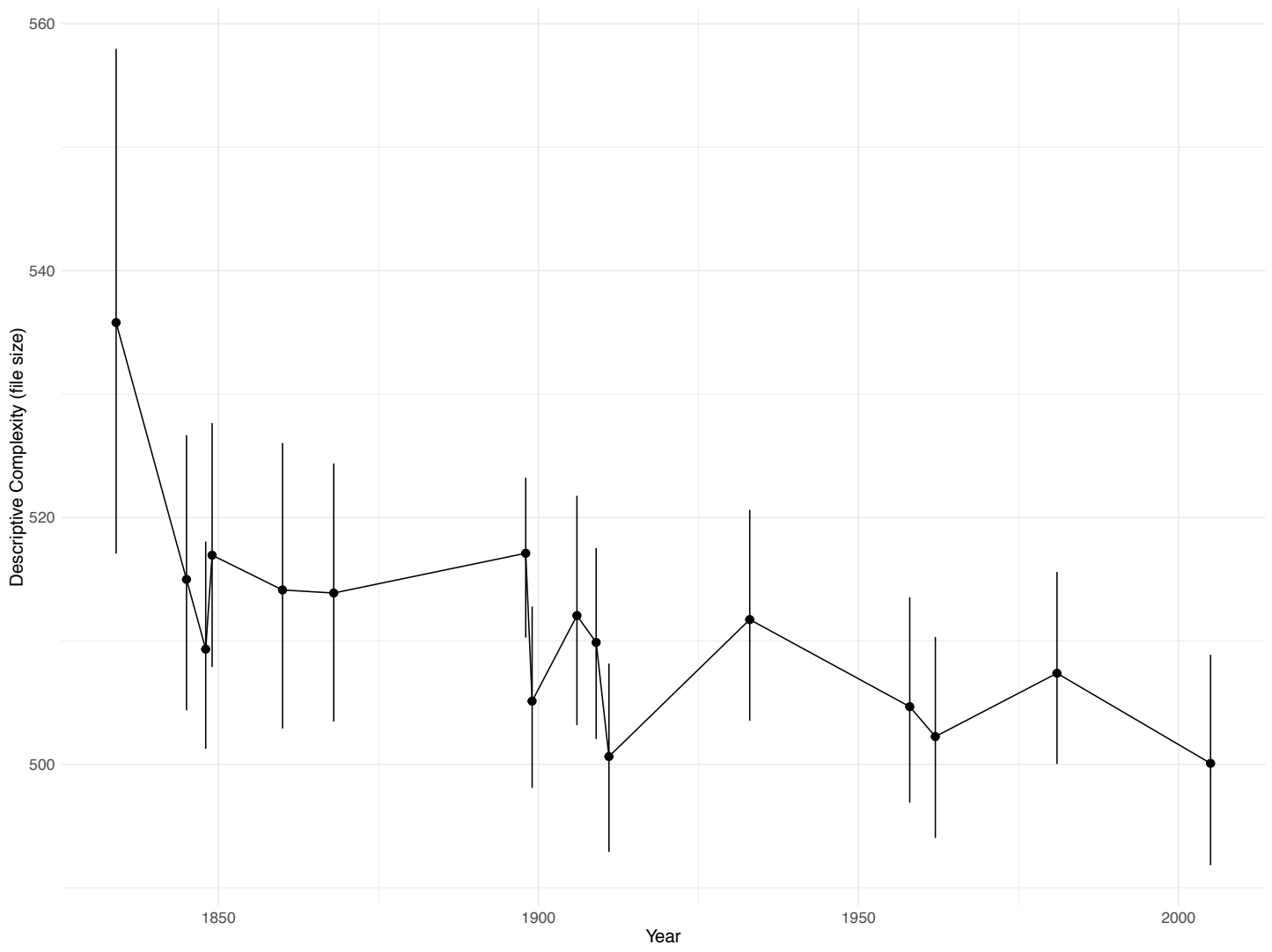

2 Figure 3. Mean descriptive complexity from 1834 to 2005. Error bars correspond to $395 \%$ CIs (bootstrapped). 


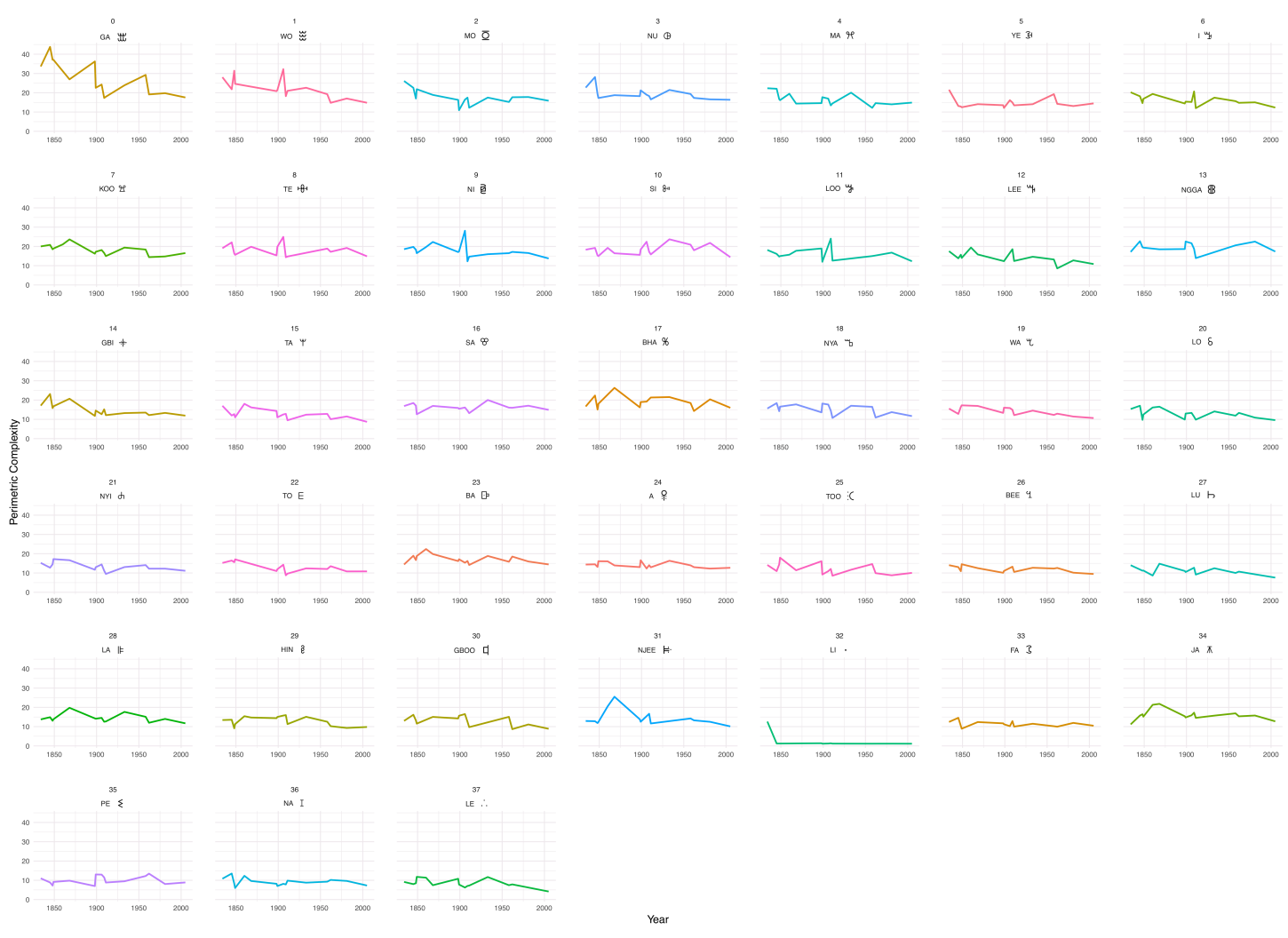

2 Figure 4. Perimetric complexity of each Vai character from 1834 to 2005 . Each facet 3 corresponds to the initial 1834 ranks in terms of perimetric complexity (i.e., 0 is the 4 highest rank and 37 is the lowest rank). Characters (A to YE) are color-coded. 

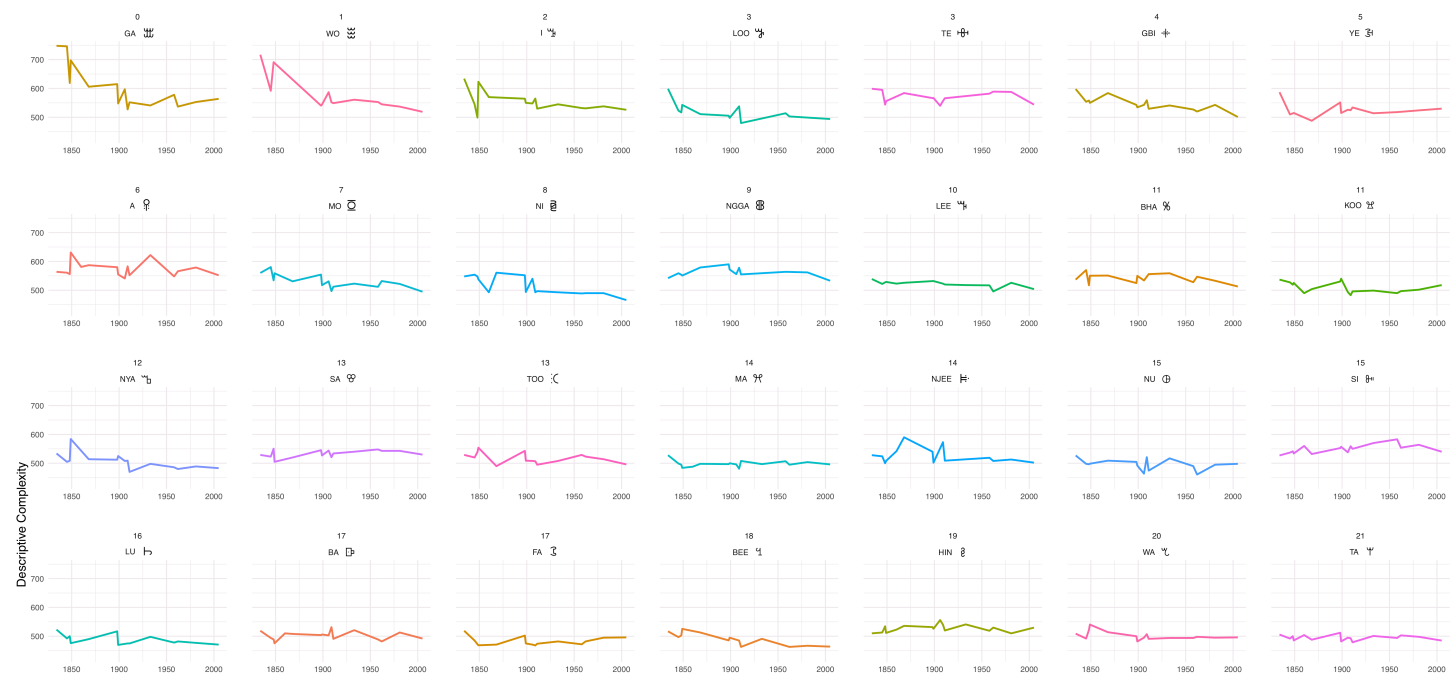

${ }^{22}{ }^{22} \mathrm{E}$

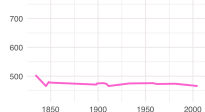

${ }^{23}$ \&
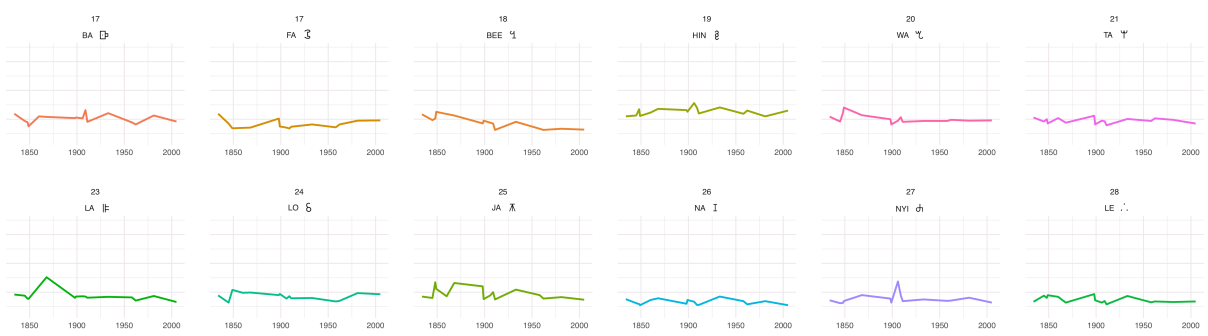

$\stackrel{29}{29} \&$

$\infty$
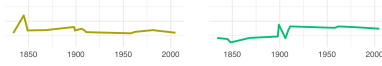

ven

Figure 5. Descriptive complexity of each Vai character from 1834 to 2005. Each facet corresponds to the initial 1834 ranks in terms of descriptive complexity (i.e., 0 is the highest rank and 31 is the lowest rank). Characters (A to YE) are color-coded. Note that some characters started out at the same level of descriptive complexity and therefore receive the same rank (e.g., rank 11).

All three of our predictions were confirmed by our results. Visual complexity decreased over successive generations, and graphemes that started out with higher visual complexity decreased more than those that began with lower visual complexity, leading to a lower variance in complexity over time. We now turn to the context and potential causes of those results.

\section{The context of compression}

14 Our study reveals that historical changes in the Vai script are far from random.

15 Instead, Vai letter forms undergo a process of compression that can be detected from the earliest years after the script's invention right up until the 21 st century. As we have seen, most studies explain compression effects in terms of transmission dynamics. As cultural items are transmitted from one user to another they pass 
1 through a memory and learning bottleneck (Bartlett [1932] 1995, Mesoudi and

2 Whiten 2004, Tamariz and Kirby 2015). The most learnable characteristics are

3 retained while features that are harder to recall or reproduce will tend to fall away.

4 Later generations of learners inherit a refined set of items which they, in turn, may

5 continue to optimize until a degree of equilibrium is achieved. Equilibrium is here

6 understood as the result of a trade-off between simplicity and distinctiveness,

7 whereby the requirement that each letter be distinctive puts a cap on the amount of

8 simplification that a letter can undergo. Each of these pressures applies to individual

9 letters, even though the pressure for distinctiveness will vary depending on the

10 number of letters in the system. In the present case, however, the size of the grapheme

11 inventory did not alter significantly across the history the system. Our study therefore

12 suggests that the compression account is highly plausible in the case of the Vai script.

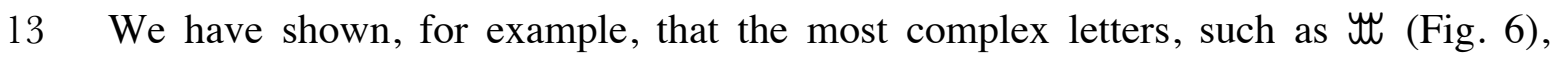

14 undergo the most dramatic changes towards simplification. Meanwhile, letters that

15 start out as relatively simple shapes tend to remain unchanged. Accordingly, high

16 levels of visual complexity would appear to act as a hindrance on the transmission of

17 the script. Of relevance here is the finding from Pelli et al. (2006) that PC is inversely

18 correlated with efficient object recognition. Thus, Vai graphemes that have lower PC

19 will be easier for readers to process, and vice versa. However, since our study relies

20 on naturalistic data outside of a controlled laboratory setting it is well worth reflecting

21 further on the historical context of Vai writing to consider whether there might be

22 other complementary - or even contrary - pressures at play across the life history of

23 the script. 


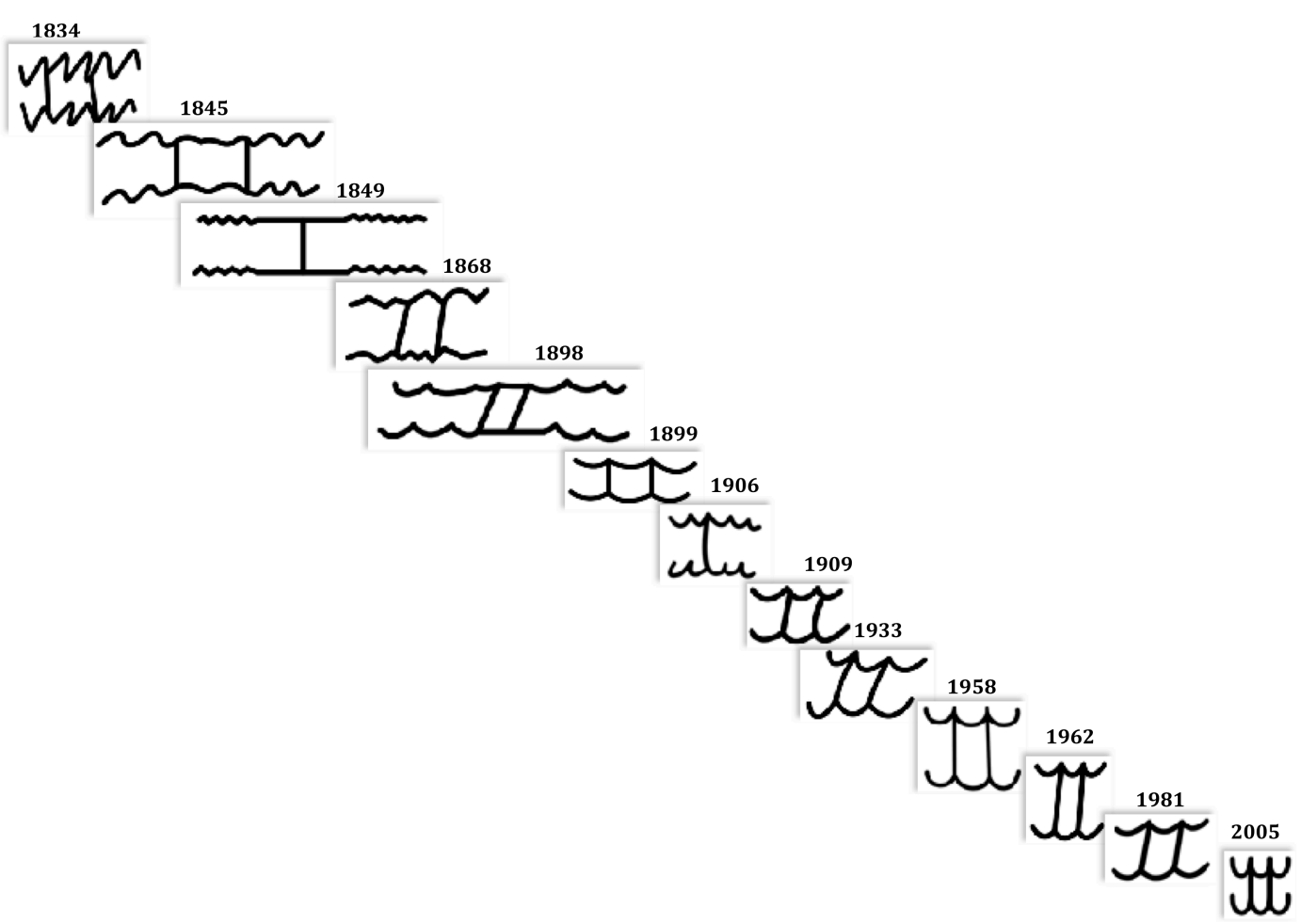

2 Figure 6 . The evolution of the complex symbol $\mathbb{M}<$ ga> between 1834 and 2005

3 A coordination problem for non-literate inventors

4 For non-literates to invent a writing system from scratch is an extraordinary cognitive

5 achievement. Writing systems have been described as cognitive tools for the analysis

6 of linguistic sound in the way that they model, and sometimes reify, phonological and

7 morphological structure (Harris 1986, Mattingly 1987, Mattingly 1992, Ferguson

8 1995, Watson and Horowitz 2011). Without such tools at their disposal, non-literate

9 inventors must figure out how to segment strings of spoken language into meaningful

10 units, lacking any means of taking notes or drawing up sound values in a reference

11 chart. As such, the eight men who developed the script in the 1830s would have had

12 to rely on their collective memories to recall the agreed-upon sounds associated with

13 each sign. With over 200 individual syllabograms, this would have required a great

14 deal of mental effort and coordination. The script development process itself can be 15 imagined as a kind of hyper-transmission event involving intensive interactions, 16 reproductions, conscious memorizations and negotiated adjustments. It is likely that 17 the inventors exploited cognitive shortcuts wherever possible. Perhaps the most 18 fundamental was their decision-deliberate or otherwise-to model single syllables 19 as opposed to either segments or multisyllabic words. The fact that non-literate 
1 inventors are inclined to invent syllable-centric systems is well established (Daniels 2 1996), a phenomenon that reflects the fact that syllables have a denser psychological reality than phonemes (Treiman and Tincoff 1997, Port 2007). Other properties of the Vai writing system as it is found in the earliest records also appear to be purpose-built for learnability. Certain characters, for example, have been modeled on traditional symbols already in use by Vai speakers, while others exploit iconicity to reference the morphemic values of a given syllable. Examples are GUN $0^{\circ} \bullet<b u>$ (representing shot pellets), WATER ח

\section{Institutions and standardization}

At least three attempts have been made to standardise the Vai script. The first was made in 1899 by Momulu Massaquoi, a descendent of the Vai script's principle inventor and a prominent Liberian intellectual and official. In this year he produced a standard chart of the Vai script for use in schools (this is represented by the point just prior to '1899' in Figs. 2 and 3 above). Twelve years later he published another chart that he claimed to be a direct reproduction of the 1899 script but which in fact shows numerous subtle variations (see '1911' on the figures above). More successful was the standardization campaign at the University of Liberia in 1962, involving eleven consultants and an official Standardization Committee. For the first time all variant graphemes were eliminated and the committee settled on one sign per syllable. The final standardization event was the Unicode proposal of 2005 (Everson, Riley, and 
1 Rivera 2005), resulting in the Vai script being accepted into the Unicode Standard

2 three years later. Those who compiled the proposal relied on the 1962 standard

3 together with modifications that reflected modern use. As we can see from the figures

4 above, each standardization event, in 1899, 1962 and 2005, coincided with a decline

5 in both descriptive and perimetric complexity suggesting a possible causal 6 relationship.

$7 \quad$ Domains and media

8 The shift from a reed stylus in proto-literate Mesopotamia to a wedge-tipped stylus in 9 the mid-third millennium necessarily resulted in a more compact and consistent cuneiform script; just as the advent of paper in early 2nd century CE China preceded the emergence of more uniform styles of Chinese writing. In like manner, technological changes in writing apparatus may have influenced the rate of compression in the Vai script. Vai was first written using pens cut from reeds with ink derived from the leaves of certain species of bush. By the end of the century, Vai writers in the interior were still using reed pens and organic inks, however those living on the coast who had better access to foreign products were writing with commercial pens and pencils on imported European paper (Delafosse 1899, 30). The Vai script was also represented on surfaces other than paper. Vai men were renowned as silversmiths, and surviving artefacts and commentaries indicate that the script was inscribed on silver ornaments. Vai has also been carved wooden tablets, furniture and lintels, a practice that continued well into the 20th century. Examples of the Vai script, apparently written with a ballpoint pen, surface in the 1970s (Scribner and Cole 1981), and by the 21st century Vai appeared in digital form as a font. It is possible that a shift from more rudimentary writing materials to modern pens and digital fonts contributed to the simplification of the script. Fonts, after all, must conform to precise dimensions and have standardized gradients for horizontal, vertical and oblique strokes. However the fact that Vai continued to compress over the entire length of the 19th century, at a time when there was little change in writing media, indicates that shifts in writing technology cannot be the full story. Even the transition from a handwritten system to a font, between 1980 and 2005, does not show a dramatically steeper decline in visual complexity than comparable time periods elsewhere in the history of the script (see Figs. 2 and 3 above). Thus while it is a possibility that letter 
1 inscription technology has influenced the compression of the script, this cannot explain our results.

After its invention, the Vai script gained popularity and became circulated more widely among Vai speakers entering into new contexts, domains and genres. Accordingly, changes in the dominant genres of Vai writing may also influence compression. Elsewhere, religious texts, or documents glorifying royal lineages, are often characterised by an abundance of visual detail. Consider, for example, the richness of Christian illuminated manuscripts, Islamic calligraphy, the Maya codices, or the monumental temple inscriptions of Egypt. These kinds of texts are not designed primarily to be read so much as displayed for the admiration literate and non-literate alike (Olivier 1981, Houston 2004a, Ferrara 2015, Guillaume-Pey 2016). By contrast, mundane or secular genres of writing often take a more simplified form, as witnessed in the bureaucratic handwriting of the hieratic and demotic scripts, or the Simplified Characters of modern China first promoted by the ultra-secularist May Fourth Movement. As it happens, the earliest recorded genres of Vai manuscripts are quite diverse, and include such documents as ordinary business transactions, historical chronicles and ornamental engravings (Payne 1860, Creswick 1868). At the end of the 19th century there are reports that the script was used for letters, travel diaries, and the recording of popular stories (Delafosse 1899, 29; Massaquoi 1899, 578). Only in the 20th century was it used in more prestigious genres such as autobiographies, compilations of aphorisms and translations of canonical literature including the Koran, the Bible, and even the Iliad (Massaquoi 1911, Dalby 1967). However, the more prosaic uses such as letter writing, record keeping, the compilation of shopping lists and the drafting of technical plans are also known across the 20th century and may have persisted from the script's earliest years. As Singer put it, "the basis for the enduring popularity of Vai [writing] has been its personal uses rather than more public ones" (Singer 1996). Consequently, nothing in the history of the script indicates a decisive shift in genres of Vai writing, or changes in writing tools, that might otherwise explain the reduction in its visual complexity.

\section{Relevance of findings to other writing systems}

31 Long before the proclamation of Liberia as a freed-slave commonwealth in 1838, Vai 32 merchants acted as agents in the cross-Atlantic slave trade, with networks stretching 
1 from the Pepper Coast into the interior. Later, as the freed slaves migrating from the

2 United States became established as the ruling ethnicity, the indigenous Vai were

3 pushed to the political margins but remained active in warfare and trade, including

4 clandestine slaving. The relative autonomy of the Vai-speaking people over centuries

5 of colonial contact may go some way to explain how they resisted domination from

6 literate populations, but were porous enough to permit their script to be documented

7 at regular intervals by outsiders. Such a delicate balance of contact and isolation has

8 resulted in a rich archival legacy that is not available to the same degree for the other

9 emergent systems invented independently in the Americas, the Pacific, and Southeast

10 Asia, not to mention elsewhere in West Africa.

11 These less-described emergent scripts, not discussed here, nonetheless exhibit 12 certain similar characteristics. On the phonological level, all emergent scripts that are 13 known to us have targeted syllables as the central unit of phonetic representation, with 14 varying degrees of primacy. Further, they have emphasised the representation of 15 consonants while underspecifying vowels (Kelly 2018). Logosyllabograms - or signs 16 standing for monosyllabic morphemes-have also featured widely in the earliest 17 beginnings of many emergent systems wherever the documentation has survived. ${ }^{16}$ 18 With the exception of the short-lived Caroline Island Script, later generations of writers worked with smaller and increasingly phonetic sets of graphemes, as $20 \log$ ograms were gradually abandoned or repurposed. As we have seen, the Vai script 21 decreased in visual complexity over the first 171 years of its history, and it remains to 22 be seen whether this process is also detectable within other emergent scripts. It is 23 nonetheless clear that the Bamum script of Cameroon and the Pahawh Hmong script 24 of Vietnam went through discrete phases at the hands of their non-literate inventors, 25 resulting in fewer strokes per character in later versions of the scripts. It would 26 appear, therefore, that emergent writing systems may well confirm the more material 27 aspects of the progressivist hypotheses supported by Gelb, Tylor, Taylor, and others, 28 even if their rigid and unilinear stadialism must be abandoned. That these thinkers 29 also assumed that writers of simpler or more phoneme-based scripts were 30 intellectually and morally superior presents another unfortunate-some might say 31 fatal-distraction from a much better-founded insight.

32 Just how well emergent systems track the trajectories of ancient primary inventions 33 of writing remains to be explored. That the Vai script was created in a conscious act 
1 by named inventors does not invalidate it as an historical heuristic. As many 2 paleographers now claim, the first writing systems are also likely to have been developed by small groups of individual specialists in the space of single generation (Boltz 1986, 28, DeFrancis 1989, 216, Michalowski 1994, Glassner 2003, Houston 2004b, Ferrara 2015, Handel 2016, but for a contrary view see Bottéro 1995). There is, after all, no such thing as a natural writing system in the same sense that we understand natural languages. All writing necessitates a degree of deliberate engineering. It is nonetheless remarkable that emergent writing systems appear to change much faster than other scripts, a phenomenon recognized by Gelb ([1952] $1963,21,210-211$ ) who suggested that their short histories emulate the evolution of writing across deeper timescales. Contrary to Gelb's teleological approach, we suggest that this apparent rapidity may be a consequence of the stimulus diffusion dynamic: since their inventors already knew what writing was capable of-including organising populations, asynchronous communication, trade facilitation, and status and identity-marking - this fore-knowledge gave them greater impetus to develop and optimize their system.

Though writing was not developed to address the bureacratic needs of states, it is nonetheless true that it would become instrumental in the regulation of state activities. One characteristic of early state complexes is a movement towards increasing uniformity and standardization of material culture. As Norman Yoffee has noted, the progressive standardization of writing in Mesopotamia coincided with other incremental uniformities in state-associated material culture, including the standardization of calendars, ration bowls, weights and measures, legal discourse, and irrigation systems (Yoffee 2001). Thus if compression effects are found in ancient writing systems these may well be subordinate to larger political convergences towards forms of state-wide 'legibility' understood in its broadest sense (Scott 1998, Downey 2014). The relative extent to which any such individual changes may be 'blind' or intentionally coordinated cannot be probed.

By contrast, the inventors and earliest generations of Vai users belonged to smaller-scale chiefdoms on the outer margins of a growing colonial complex; the first

31 official standardization efforts were not enacted until Vai populations had become integrated into the Liberian colony. Even though it has never been deployed to fulfil the demands of mass-production within a complex state infrastructure, the Vai script 
1 has nonetheless transitioned towards greater visual simplicity and regularity across all

2 phases of its history.

\section{Limitations of the study}

4 One of the advantages of Vai as an object of study is the fact that its grapheme 5 inventory of around 200 letters has remained fairly stable over its entire history. 6 However this fact also places limits on its heuristic value. The cuneiform, Egyptian and Chinese systems have witnessed significant fluctuations in inventory size over their much longer histories with implications for visual complexity. As Isaac Taylor put it, "a change in any one letter constantly produces related changes in other letters - they have to be differentiated in order to maintain an adequate dissemblance" (Taylor 1883b, 365). Thus, as grapheme inventories of writing systems expand and contract at different points in their history, we can expect individual graphemes to maintain or increase their complexity in order to ensure that no two graphemes look too alike within a limited design space. As Watson's analysis indicated, individual letters of the comparatively small Roman alphabet are, on average, much simpler than those of the much larger Chinese script (Watson 2012). Expansions and contractions to grapheme inventories also raise the question of system-wide compression effects and how they might be detected. ${ }^{17}$ System-internal effects, in which similarities and distinctions between letters become structurally organized within the system as a whole, could not be investigated in our study. However, if adequate concordance tables were available for sequential phases of ancient writing systems, this would present an opportunity to detect system-wide compression by measuring and controlling for grapheme inventory size. Such a study would help to bring precision to the question of how individual graphemes within a fluctuating system must strike "compromise between reduction of effort and distinctiveness" (McArthur 1992, 341).

\section{Conclusion}

As we have seen, scholars have long drawn attention to incremental processes of simplification in historical writing systems, and some have suggested that these dynamics might also be found in emergent systems created by non-literates. Our study of the emergent Vai script has detected clear compression effects over the first 171

31 years of its existence, corroborating the simplification hypothesis. These effects are 
witnessed in the fact that visual complexity decreases over successive generations of users, and that graphemes with higher visual complexity decrease more than graphemes with initially lower complexity. Further, we have demonstrated that the overall breadth of variation in Vai graphemes decreases with time. In other words, the complexity rates of Vai graphemes become increasingly uniform with respect to one another. We have argued that historical considerations, such as standardization campaigns, changes in writing technology and genres, cannot by themselves explain the consistent reduction in visual complexity over the life of the script. Following the lead of earlier paleographic theorists, we suggest that systematic compression may well be a central dynamic underpinning the early evolution of writing systems.

\section{Acknowledgments}

With thanks to Jeremiah Williams of Monrovia and Bai Leesor Sherman (University of Liberia) of Bendu for details concerning the present uses of the Vai script and its recent history. Olena Tykhostup (Friedrich Schiller Universität, Jena) tabulated Vai graphemes, and Julia Bespamyatnyk (Universität Erfurt) traced them as .svgs. Thanks also to the Houghton Library, Harvard, for access to rare Vai manuscripts.

\section{References}

Altenmüller, Hartwig. 2005. Einführung in die Hieroglyphenschrift. Hamburg: Buske. Baines, John. 2007. Visual and written culture in ancient Egypt. Oxford: Oxford University Press.

Balfour, Henry. 1893. The evolution of decorative art. New York: Macmillan.

Bartlett, F. C. [1932] 1995. Remembering: A study in experimental and social psychology. Cambridge: Cambridge University Press.

Bates, Douglas, Martin Mächler, Ben Bolker, and Steve Walker. 2014. "Fitting linear mixed-effects models using lme4." arXiv preprint arXiv:1406.5823.

Boltz, William G. 1986. "Early Chinese writing." World Archaeology 17 (3):420436.

Boone, Elizabeth Hill. 1994. "Introduction: Writing and recording knowledge." In Writing without words: Alternative literacies in Mesoamerica and the Andes, edited by Elizabeth Hill Boone and Walter D Mignolo, 3-26. Durham \& London: Duke University Press.

Bottéro, Jean. 1995. Mesopotamia: Writing, reasoning, and the gods. Chicago \& London: University of Chicago Press.

Breuil, Henri. 1905. "La dégénérescence des figures d'animaux en motifs ornementaux à l'époque du renne." Comptes rendus des séances de I'Académie des Inscriptions et Belles-Lettres 49:105-120.

Caldwell, Christine A, and Kenny Smith. 2012. "Cultural evolution and perpetuation of arbitrary communicative conventions in experimental microsocieties." PloS one 7 (8):e43807. 
Carr, John W, Kenny Smith, Hannah Cornish, and Simon Kirby. 2017. "The cultural evolution of structured languages in an open-ended, continuous world." Cognitive Science 41 (4):892-923.

Champollion, Jean-François. 1824. Précis du système hiéroglyphique des anciens égyptiens, ou, Recherche sur les éléments premiers de cette écriture sacrée. Paris: Treuttel \& Würtz.

Champollion, Jean-François. 1836. Grammaire Égyptienne, ou principes généraux de l'écriture sacrée égyptienne appliquée à la représentation de la langue parlée. Paris: Firmin Dido Frères.

Changizi, Mark A, and Shinsuke Shimojo. 2005. "Character complexity and redundancy in writing systems over human history." Proceedings of the Royal Society of London B: Biological Sciences 272 (1560):267-275.

Claidière, Nicolas, Gameli Kodjo-kuma Amedon, Jean-Baptiste André, Simon Kirby, Kenny Smith, Dan Sperber, and Joël Fagot. 2018. "Convergent transformation and selection in cultural evolution." Evolution and Human Behavior 39 (2):191-202.

Clodd, Edward. 1900. The story of the alphabet. London: George Newnes.

Cohen, Marcel. 1958. La grande invention de l'écriture et son évolution. Paris: Imprimerie Nationale Librerie C. Klincksiek.

Dalby, David. 1967. "A survey of the indigenous scripts of Liberia and Sierra Leone: Vai, Mende, Loma, Kpelle and Bassa." In African Language Studies, edited by Malcolm Guthrie, 1-51. London: School of Oriental and African Studies.

Daniels, Peter T. 1992. "The syllabic origin of writing and the segmental origin of the alphabet." In The linguistics of literacy, edited by Pamela Downing, Susan D Lima and Michael Noonan, 83-110. Amsterdam: John Benjamins.

Daniels, Peter T. 1996. "The invention of writing." In The world's writing systems, edited by Peter T Daniels and William Bright. New York \& Oxford: Oxford University Press.

DeFrancis, John. 1989. Visible speech: The diverse oneness of writing systems. Honolulu: University of Hawaii Press.

Dehaene, Stanislas. 2009. Reading in the brain: The science and evolution of a human invention. New York: Viking.

Delafosse, Maurice. 1899. Les Vaï: Leur langue et leur système d'écriture. Paris: Maison.

Diringer, David. [1948] 1968. The alphabet: A key to the history of mankind. London: Hutchinson of London.

Downey, Greg. 2014. "All forms of writing." Mind \& Language 29 (3):304-319.

Dugast, Idelette, and M. David W Jeffreys. 1950. L'écriture des Bamum: Sa naissance, son évolution, sa valeur phonétique, son utilisation. Paris: Mémoires de l'Institut Français d'Afrique Noire.

Ege, Otto F. 1921. The story of the alphabet. Baltimore, Maryland: Norman T. A. Munder.

Evans, Arthur J. 1909. Scripta Minoa: The written documents of Minoan Crete with special reference to the archives of Knossos. 2 vols. Vol. 1. Oxford: The Clarendon Press.

Everson, Michael, Charles Riley, and José Rivera. 2005. "Proposal to add the Vai script to the BMP of the UCS." Universal Multiple-Octet Coded Character Set International Organization for Standardization ISO/IEC JTC1/SC2/WG2 N2948R: L2/05-159R.

Fehér, Olga, Haibin Wang, Sigal Saar, Partha P Mitra, and Ofer Tchernichovski. 2009. "De novo establishment of wild-type song culture in the zebra finch." Nature 459 (7246):564.

Ferguson, Charles A. 1995. "Review of Smalley et al." Word 46 (1):75-88.

Ferrara, Silvia. 2014. "Desecrating signs: 'hieroglyphic' writing systems and secondary script inventions." In $A \Theta \Upsilon P M A T A$ : Critical essays on the archaeology of the Eastern Mediterranean in honour of E. Susan Sherratt, 
edited by Yannis Galanakis, Toby Wilkinson and John Bennet, 73-79. Oxford: Archaeopress.

Ferrara, Silvia. 2015. "The beginnings of writing on Crete: Theory and context." The Annual of the British School at Athens 110:27-49.

Forbes, F. E. 1851. "Despatch communicating the discovery of a native written character at Bohmar, on the Western Coast of Africa, near Liberia, accompanied by a vocabulary of the Vahie or Vei tongue." Journal of the Royal Geographical Society of London 20:89-101.

Garrod, Simon, Nicolas Fay, John Lee, Jon Oberlander, and Tracy MacLeod. 2007. "Foundations of representation: Where might graphical symbol systems come from?" Cognitive Science 31 (6):961-987.

Gelb, I.J. [1952] 1963. A study of writing. 2 ed. Chicago: University of Chicago Press.

Glassner, Jean-Jacques. 2003. The invention of cuneiform: Writing in Sumer [Écrire à Sumer: L'invention de cunéiforme]. Translated by Zainab Bahrani and Marc van de Meiroop. Baltimore \& London: John Hopkins University Press.

Goedicke, Hans. 1988. Old hieratic paleography. Baltimore, Maryland: Halgo.

Guillaume-Pey, Cécile. 2016. "Boire des lettres ou converser avec les esprits? Tensions rituelles autour de l'appropriation de l'écriture chez les Sora (Inde)." ethnographiques.org (33).

Handel, Zev. 2016. "Does Xǔ Shèn's Huìỳ category reflect historical reality? An argument for the existence of compound graphs lacking phonophorics." In New Horizons in the Study of Chinese Dialectology, Grammar, and Philology: Studies in Honor of Professor Anne Yue, edited by Pang-hsin Ting, Samuel Hung-nin Cheung, Sze-Wing Tang and Andy Chin, 581-598. Hong Kong: T.T. Ng Chinese Language Research Centre, Institute of Chinese Studies, The Chinese University of Hong Kong.

Harris, Roy. 1986. The origin of writing. London: Duckworth.

Hegenbarth-Reichardt, Ina, and Gabriel Altmann. 2008. "On the decrease of complexity from hieroglyphs to hieratic symbols." In Analyses of script: Properties of characters and writing systems, edited by Gabriel Altmann and Fan Fengxian, 105-114. Berlin \& New York: Mouton de Gruyter.

Houston, Stephen D. 2004a. "Final thoughts on first writing." In The first writing: Script invention as history and process, edited by Stephen Houston, 349-353. Cambridge: Cambridge University Press.

Houston, Stephen D. 2004b. "Overture to the first writing." In The first writing: Script invention as history and process, edited by Stephen Houston, 3-15. Cambridge: Cambridge University Press.

Houston, Stephen D. 2004c. "Writing in early Mesoamerica." In The first writing: Script invention as history and process, edited by Stephen D. Houston, 274309. Cambridge: Cambridge University Press.

Kalish, Michael L, Thomas L Griffiths, and Stephan Lewandowsky. 2007. "Iterated learning: Intergenerational knowledge transmission reveals inductive biases." Psychonomic Bulletin \& Review 14 (2):288-294.

Kandakai, Zuke, S. Jargaba Johnson, Bai Tamia Moore, and Fatima Massaquoi Fahnbulleh. 1962. The standard Vai script. Liberia: The University of Liberia African Studies Program.

Kelly, Piers. 2018. "The invention, transmission and evolution of writing: Insights from the new scripts of West Africa." In Paths into script formation in the ancient Mediterranean, edited by Silvia Ferrara and Miguel Valério, 189-209. Rome: Studi Micenei ed Egeo Anatolici.

Kelly, Piers. forthcoming. "The invention, transmission and evolution of writing: Insights from the new scripts of West Africa." In Paths into script formation in the ancient Mediterranean, edited by Silvia Ferrara and Miguel Valério. Rome: Studi Micenei ed Egeo Anatolici.

Kotei, S. I. A. 1972. "The West African autochthonous alphabets: An exercise in comparative palaeography." Ghana Social Science Journal 2 (1):98-110. 
Kroeber, A. L. 1940. "Stimulus diffusion." American Anthropologist 42 (1):1-20.

Mason, William A. 1928. A history of the art of writing. New York: The Macmillan Company.

Massaquoi, Momolu. 1899. "The Vey language." The Spirit of Missions 64:577-579.

Massaquoi, Momolu. 1911. "The Vai people and their syllabic writing." Journal of the Royal African Society 10 (40):459-466.

Mattingly, Ignatius. 1992. "Linguistic awareness and orthographic form." Haskins Laboratory Status Report on Speech Research SR109/110:129-140.

Mattingly, Ignatius G. 1987. "Morphological structure and segmental awareness." Cahiers de psychologie cognitive 7:488-493.

McArthur, Douglas. 1992. "Motivation in the forms of signs." Sign Language Studies 77:339-344.

McDougall, Siné JP, Martin B Curry, and Oscar de Bruijn. 1999. "Measuring symbol and icon characteristics: Norms for concreteness, complexity, meaningfulness, familiarity, and semantic distance for 239 symbols." Behavior Research Methods, Instruments, \& Computers 31 (3):487-519.

McManus, Damian. 1996. "Ogham." In The world's writing systems, edited by Peter $\mathrm{T}$ Daniels and William Bright, 340-345. New York \& Oxford: Oxford University Press.

Mesoudi, Alex, and Andrew Whiten. 2004. "The hierarchical transformation of event knowledge in human cultural transmission." Journal of cognition and culture $4(1): 1-24$.

Michalowski, Piotr. 1994. "Writing and literacy in early states: A Mesopotamianist perspective." In Literacy: Interdisciplinary conversations, edited by Deborah Keller-Cohen, 49-70. Cresskill, N.J.: Hampton Press.

Mignolo, Walter D. 1989. "Literacy and colonization: The new world experience." In 1492/1992: Re/Discovering Colonial Writing, edited by $\mathrm{R}$ Jara and N Sapadaccini, 51-96. Minneapolis: Prisma Institute.

Miton, Helena, Nicolas Claidière, and Hugo Mercier. 2015. "Universal cognitive mechanisms explain the cultural success of bloodletting." Evolution and Human Behavior 36 (4):303-312.

Miton, Helena, and Olivier Morin. 2019. "When iconicity stands in the way of abbreviation: No Zipfian effect for figurative signals." PloS one 14 (8):e0220793.

Morphy, Howard. 1991. Ancestral connections: Art and an Aboriginal system of knowledge. Chicago: University of Chicago Press.

Olivier, Jean-Pierre. 1981. "Les sceaux avec des signes hiéroglyphiques: que lire? Une question de définition." In Studien zur minoischen und helladischen Glyptik: Beiträge zum 2. Marburger Siegel-Symposium 26-30 September 1978, edited by Ingo Pini, 105-115. Berlin: G. Mann.

Parker, Heather Dana Davis, and Christopher A Rollston. 2016. "The epigraphic digital lab: Teaching epigraphy in the twenty-first century CE." Near Eastern Archaeology 79 (1):44-56.

Pauthier, Guillaume. 1838. De l'origine et de la formation des differens systèmes d'écritures orientales et occidentales: Article extrait de l'Encyclopédie Nouvelle. Vol. 1. Paris: Bourgogne et Martinet.

Pelli, Denis G, Catherine W Burns, Bart Farell, and Deborah C Moore-Page. 2006. "Feature detection and letter identification." Vision research 46 (28):46464674.

Philippe, Jean. 1897. "Sur les transformations de nos images mentales." Revue Philosophique de la France et de l'Étranger 43:481-493.

Pitt-Rivers, A. Lane-Fox. [1875] 1906. "On the evolution of culture." In The evolution of culture and other essays, edited by J. L. Myres, 20-44. Oxford: Clarendon Press.

Port, Robert. 2007. "How are words stored in memory? Beyond phones and phonemes." New ideas in psychology 25 (2):143-170. 
Regier, Terry, Charles Kemp, and Paul Kay. 2014. "Word meanings across languages support efficient communication." In The Handbook of Language Emergence, edited by B MacWhinney and W O'Grady, 237-263. Hoboken: WileyBlackwell.

Ritschl, F. 1869. "Zur Geschichte des lateinischen Alphabets." Rheinisches Museum für Philologie 24:1-32.

Rousseau, Jean-Jacques. [1781] 1966. On the origin of language: Two essays by JeanJacques Rousseau and Johann Gottfried Herder. Translated by John H Moran and Alexander Gode. New York: Frederick Ungar.

Rovenchak, Andrij , Ján Mačutek, and Charles Riley. 2009. "Distribution of complexities in the Vai script." Glottometrics 18:1-12. doi: arXiv:0810.0200.

Rovenchak, Andrij, Charles Riley, and Tombekai Sherman. 2011. "Complexity of the Vai script revisited: A frequency study of the syllabary." In Issues in Quantitative Linguistics 2, edited by Emmerich Kelih , Victor Levickij and Yuliya Matskulyak Lüdenscheid: RAM Verlag.

Scott, James C. 1998. Seeing like a state: How certain schemes to improve the human condition have failed. New Haven \& London: Yale University Press.

Scribner, Sylvia, and Michael Cole. 1981. The psychology of literacy. Cambridge, Mass.: Harvard University Press.

Steele, Philippa M. 2017. "Writing «systems»: Literacy and the transmission of writing in non-administrative contexts." In Non-scribal communication media in the Bronze Age Aegean and surrounding areas: The semantics of a-literate and proto-literate media (seals, potmarks, mason's marks, seal-impressed pottery, ideograms and logograms, and related systems), edited by Anna Margherita Jasink, Judith Weingarten and Silvia Ferrara, 153-172. Florence: Firenze University Press.

Tamariz, Monica. 2017. "Experimental studies on the cultural evolution of language." Annual Review of Linguistics 3:389-407.

Tamariz, Mónica, and Simon Kirby. 2015. "Culture: Copying, compression, and conventionality." Cognitive Science 39 (1):171-183. doi: $10.1111 / \operatorname{cogs} .12144$.

Taylor, Isaac. 1883a. The alphabet: An account of the origin and development of letters. 2 vols. Vol. 1. London: Kegan Paul, Trench, \& Co.

Taylor, Isaac. 1883b. The alphabet: An account of the origin and development of letters. 2 vols. Vol. 2. London: Kegan Paul, Trench, \& Co.

Treiman, Rebecca, and Ruth Tincoff. 1997. "The fragility of the alphabetic principle: Children's knowledge of letter names can cause them to spell syllabically rather than alphabetically." Journal of Experimental Child Psychology 64:425-451.

Trigger, Bruce G. 2003. Understanding early civilizations. Cambridge, UK: Cambridge University Press.

Turoman, Nora, and Suzy J Styles. 2017. "Glyph guessing for 'oo'and 'ee': spatial frequency information in sound symbolic matching for ancient and unfamiliar scripts." Royal Society open science 4 (9):170882.

Tykhostup, Olena, and Piers Kelly. 2018. "A diachronic comparison of the Vai script of Liberia (1834-2005)." Journal of Open Humanities Data 4:2. doi: http://doi.org/10.5334/johd.10.

Tylor, Edward B. [1865] 1878. Researches into the early history of mankind and the development of civilization. Boston: Estes \& Lauriat.

von Petzinger, Genevieve. 2016. The first signs: Unlocking the mysteries of the world's oldest symbols. New York: Atria.

Walker, Willard, and James Sarbaugh. 1993. "The early history of the Cherokee syllabary." Ethnohistory 40 (1):70-94.

Watson, Andrew B. 2012. "Perimetric complexity of binary digital images: Notes on calculation and relation to visual complexity." The Mathematica Journal 14:140 . 
Watson, Rita, and Wayne Horowitz. 2011. Writing science before the Greeks. Leiden \& Boston: Brill.

Yoffee, Norman. 2001. "The evolution of simplicity." Current Anthropology 42 (5):765-767.

Zipf, George Kingsley. 1949. Human behavior and the principle of least effort: An introduction to human ecology. Cambridge, Mass: Addison-Wesley Press.

. "The fact that historical changes within a script are not a matter of chance or arbitrariness, but rather are associated with an internal development that progresses according to certain laws or guiding impulses is surely indisputable: it is on this insight that the whole concept of scientific 'paleography' is based." (Dass die geschichtlichen Veränderungen einer Schrift nicht Sache des Zufalls oder der Willkür sind, sondern viel-mehr im Zusammenhange einer innern Entwicklung stehen, die nach gewissen bestimmenden Gesetzen oder doch leitenden Trieben vor sich geht, wird wohl im allgemeinen von niemand verkannt: wie denn auf dieser Einsicht der ganze Begriff einer wissenschaftlichen 'Paläographie' beruht).

Perhaps the greatest champion for this theory was the epigrapher Arthur Evans whose Scripta Minoa (1909) proposed a much deeper lineage for writing than any of his predecessors. While the Paleolithic archeologist Henri Breuil was prepared to suggest that stylistic transitions in Magdalenian rock art were analogous to the evolution of writing (Breuil 1905), Evans hinted at a much more direct historical pathway. Referring to Breuil's sketches, he wrote that "[s]igns of curiously alphabetic aspect-at times even in groups-are seen engraved on reindeer-horns or ivory, or on the surface of the rock itself [...] Certain signs carved on a fragment of reindeer horn are specially interesting from the primitive anticipation that they present of the Phoenician alef." (Evans 1909, 3-4). Even today, a presumed relationship between geometric signs in rock art and modern writing continues to be entertained (see for example von Petzinger 2016).

Bartlett noted that in transmission chain experiments, "some element of an original complex gradually attains a more and more important position and comes to stand for all the rest. The long story of the development of the common alphabetical forms is a case in point" (271). It is in this light that we should read his choice Egyptian owl hieroglyphic $/ \mathrm{m} /$ as the starting stimulus in a transmission chain, noting that it "may have been the basis of the form of our letter M" (180), as derived from M-like beak and face. In fact, his participants transformed it into cat.

-As Silvia Ferrara's put it, "[i]ncipits of all script are invisible, as our points of departure are irrevocably not 'the first' attestations, but the 'earliest' that the vagaries of archaeological preservation has made available to us" (Ferrara 2014, 75).

It is often noted that writing systems have a bias towards inertia. The clearest demonstration of this can be seen when a writing system developed by speakers of a given language is later appropriated for use by speakers of a language with dissimilar phonological or morphological rules. In many cases, features of the system designed for the first language are retained for the new language, despite increased costs in terms of accuracy and learnability. Consider how the Minoan syllabic system was appropriated for Mycenean Greek despite the latter's preponderance of consonant clusters (Mattingly 1992). Or the fact that Turkish was, for centuries, represented in the Arabic 
script, which is well suited to Semitic languages, with consonantal roots and inflecting vowels, but not to the phonotactics of Turkish. However, when writing systems are actively reformed to accommodate the phonologies of their new languages, these reforms often result in the more precise specification of phonological units, for example from Sumerian cuneiform to the more phonetic Akkadian cuneiform, or in the shift from the Phoenician script (specifying consonants) to the Greek alphabet (specifying both consonants and vowels).

'Note that the term 'emergent' is not defined historically, so there is no categorical cut-off point distinguishing emergent scripts from primary scripts on the basis of periodization; indeed several ancient scripts are argued to have been emergent, including Linear A and Old Persian Cuneiform. Daniels introduced the term 'unsophisticated grammatogenies' for such scripts, which we believe is misleading since it lends the impression that they were naively or deficiently constructed.

Although unsuccessful attempts have been made to detect influences from systems as disparate as Arabic, Hebrew and Chinese (for a summary see Kelly forthcoming), the Vai script is very much a 'closed' writing system (Houston 2004c) with no discernible interference from other writing traditions.

" Momolu Massaquoi complained that before he drew up his 'standard' chart of Vai signs "[e]ach man [...] began the study of the characters where he liked and ended where liked, few ever mastering the whole." (Massaquoi 1899, 578). However, Tuchscherer's observations confirm that these efforts had limit impact on traditional ad hoc learning methods.

, The left-hand image is catalogued as "New invented native alphabet of Western Africa Recd. April 18, 1834 from Messrs Wilson and Wynkoop,” MS. Vai 1, page 1. Houghton Library, Harvard University. It is reproduced by permission of the United Church of Christ Wider Church Ministries. The right hand image is rendered in the unicode standard using the Dukor font developed by Jason Glavy. (Not all 1834 graphemes are attested in 2005; spaces indicate omissions.)

10 All materials can be accessed at https://figshare.com/articles/Comparison_chart_of_Vai_script/5398537

"We use the Watson instantiation of PC because it controls for the limited resolution of the visual system, unlike the measure derived from Pelli et al (2006).

${ }^{12}$ Year was transformed so that it starts at 0 (i.e., $1834=0$ ). This transformation preserves the absolute change in time (e.g., $1834=0,1845=11,1848=14$ etc)

${ }^{1}$ To assess the fit of the models we used Akaike Information Criterion (AIC) and Bayesian Information Criterion (BIC). AIC and BIC are estimators of model fit, taking into account the number of parameters for a given set of data (i.e., the tradeoff between a parsimonious and an accurate model). The main difference between the two is that BIC penalizes violations of parsimony more stringently than AIC.

${ }^{14}$ For DC some of the characters share exactly the same file size. As such, these characters receive the same rank 
"Drawing on progressivist models, a number of scholars speculated that ideographic or pictographic system must have prefigured the development of the phonetic Vai script (Massaquoi 1911, Diringer [1948] 1968, Kotei 1972).

${ }^{16}$ Historians maintain that Sequoyah first developed a logographic system for Cherokee before launching his fully syllabary in 1821 (Walker and Sarbaugh 1993). In the earliest years of its development in ca. 1896, the Bamum script of Cameroon was comprised of 460 logograms but transitioned through five stages until it became a fully phonetic system of 80 signs (Dugast and Jeffreys 1950, 24). The Alaska script developed between 1901-1905, relied first on indigenous pictograms with no phonetic values, before its inventor reformed it as a syllabary. The Caroline Islands script (1905-1909) was phonetic from the beginning but included many iconic logograms. Similarly, Pahawh Hmong (Vietnam, 1955-1971) became increasingly precise but was phonetic from the outset, with a small set of logograms used only for numbers and certain common words. The earliest drafts of the Masaba script (Mali, 1930) are lost, and the surviving documents show a fully phonetic script (Kelly forthcoming).

"Again, Taylor preempted this question when noted that "Of an opposite tendency [to differentiation] is the principle of assimilation, which often produces curious superficial resemblances among letters belonging to the same alphabet, affecting, more especially, contiguous letters such as $\mathrm{m}$ and n, p and q, E and F." (Taylor 1883b, 365). 